\title{
Trabajo y subjetivación política: desafíos epistemometodológicos
}

Labor and political subjectivation: epistemological and methodological challenges

\author{
Inés Montarcé \\ Instituto de Ciencias Humanas, Sociales y Ambientales (INCIHUSA), \\ Consejo Nacional Cientifico Tecnológico, Argentina \\ imontarce@gmail.com
}

\begin{abstract}
Resumen:
La inquietud por comprender los procesos de subjetivación política que surgen al calor de los movimientos sociales contemporáneos ha generado debates en los que se ponen en discusión tradiciones teóricas, epistemológicas y metodológicas diferentes. En este artículo se revisan los aportes de autores insertos dentro de corrientes críticas con la intención de construir herramientas que orienten el abordaje metodológico de las subjetividades que emergen en torno a experiencias concretas de acción y organización laboral. Finalmente, se analizan dichas propuestas a la luz de una investigación empírica llevada a cabo en la Ciudad de México.
\end{abstract}

Palabras ClaVe: Metodología, Conflictividad laboral, Subjetividades colectivas.

\begin{abstract}
:
The concern to understand the processes of political subjectivation that arise in the heat of contemporary social movements has generated debates in which different theoretical, epistemological and methodological traditions are discussed. In this article we review the contributions of authors inserted in critical currents with the intention of building tools that guide the methodological approach of subjectivities that emerge around concrete experiences of action and labour organization. Finally, these proposals are analyzed considering an empirical research carried out in Mexico City.
\end{abstract}

KEYWORDS: Methodology, Labor conflict, Collective subjectivities.

\section{INTRODUCCIÓN}

Hablar de subjetividades colectivas en relación al trabajo supone preguntarnos por los procesos a través de los cuales los/as trabajadores/as construyen sus modos particulares de ser, estar, pensar, dar sentido y actuar en relación a las experiencias prácticas en las que se desenvuelven. Dichas producciones son sociales, ya que la capacidad de afectar y ser afectado se va construyendo en la complejidad de las relaciones cotidianas, en el marco de contextos culturales, económicos, sociales y políticos más amplios. Que estén condicionadas no supone que estén determinadas, ya que la creación de significados es dinámica y existe la posibilidad de que se creen sentidos que disputen las estructuras simbólicas dominantes. Esto quiere decir que siempre pueden darse, por parte de los/as trabajadores/as, rupturas y líneas de fuga en las formas subjetivas de existencia. En este marco, retomamos el concepto de subjetivación política para referir a los procesos colectivos anclados en prácticas transformadoras que subvierten las estructuras de significación hegemónicas y crean sentidos disruptivos, más allá de su alcance y grado de formalización y/o institucionalización.

Si entendemos a "lo político" como una dimensión fundamental de toda sociabilidad humana (Echeverría, 1996), hay que reconocer que no se reduce a las disputas institucionalizadas en el ámbito estatal, sino que abarca todas aquellas singularidades, estrategias y modos de existencia que se ponen en juego en las prácticas cotidianas y que suponen movilizaciones específicas de sentidos con mayor o menor grado de tensión. Trasladadas al ámbito laboral, estas discusiones adquieren nuevas acepciones: la heterogeneidad 
de condiciones que atraviesa al mundo del trabajo actual ha multiplicado los escenarios de conflicto con repercusiones concretas en la subjetivación. Ya no es posible pensar en un sujeto homogéneo (la idea de una clase obrera unificada), sino que es necesario reconocer las múltiples afecciones que atraviesan los espacios laborales entendiendo que la irrupción de sensibilidades antagónicas no implica la construcción de formas específicas de conciencia.

Para abordar dichos procesos creemos que es necesario asumir un enfoque micropolítico que reconozca la multiplicidad de formas que pueden adquirir los antagonismos cotidianos. Para ello, deben considerarse no solo las expresiones visibles y públicas de la conflictividad sino también sus manifestaciones soterradas. Esto constituye un enfoque que trasciende la visión clásica centrada en los repertorios tradicionales de acción sindical. Al respecto, las tradiciones marxistas y foucaultianas-deleuzianas han sentado bases teóricas para una mirada crítica de la dinámica de las relaciones de fuerzas en los espacios laborales, por lo que la articulación de los criterios teóricos y metodológicos establecidos en ambos enfoques se vuelve clave para interrogar los antagonismos emergentes.

En este artículo revisamos las propuestas realizadas por autores latinoamericanos insertos dentro de dichas corrientes (Hugo Zemelman, Enrique De la Garza, Massimo Modonesi y Claudia Piedrahita) con la intención de construir herramientas que nos posibiliten analizar la urdimbre de afecciones y sensibilidades colectivas que emergen en los espacios productivos. Comenzamos problematizando la categoría de subjetivación política, para luego reflexionar acerca de las implicaciones epistemometodológicas que subyacen a tales enfoques, y las posibles estrategias a implementar en situaciones concretas. Finalmente, se buscan articulaciones posibles entre dichas perspectivas tomando como referencia una investigación realizada en call centers de la Ciudad de México.

\section{ACERCA DE LA SUBJETIVACión}

Desde una perspectiva marxista latinoamericana, tanto la teoría de la reconstrucción articulada (Zemelman, 1987, 2012) como el configuracionismo (De la Garza, 2001, 2018) proponen una matriz analítica crítica para el estudio de los procesos de subjetivación política. El eje de ambos enfoques está puesto en la necesidad de desarrollar análisis del tiempo presente que no dependan de la determinación de leyes históricas, sino que capten el devenir de las prácticas individuales y colectivas en su propio dinamismo.

A partir de la concepción de que la realidad social es una totalidad concreta en continuo movimiento, Hugo Zemelman (1987) sustituye la noción positivista de predicción por la categoría de posibilidad, lo que supone pensar que la construcción de lo subjetivo no deriva de mecanismos estructurales, sino que depende de las potencialidades que inauguran las propias prácticas en el marco de coyunturas específicas que definen horizontes de acción viables. Esto quiere decir que, si bien las subjetividades políticas no están determinadas ni obedecen a lógicas particulares, tampoco se consideran del todo contingentes o azarosas, dado que en cada momento histórico existen ámbitos de posibilidades que definen voluntades de acciones transformadoras socialmente factibles. Es a través de tales voluntades que se expanden las subjetividades y se puede hablar del hombre-sujeto consciente (Zemelman, 2012, p. 244).

En la misma línea, Enrique De la Garza (2001) reconoce que los procesos subjetivos no se dan enteramente en el plano de la conciencia, así como tampoco refieren estrictamente a la individualidad de las personas, sino que se construyen en la complejidad de las interacciones cotidianas, en el marco de estructuras culturales, económicas, sociales y políticas que condicionan las formas de significación, aunque no las determinan. La subjetividad es entendida como el proceso social y dinámico a través del cual las personas movilizan y resignifican ciertos códigos culturales para dar sentido a la situación concreta y decidir la acción. En ese sentido, mientras la cultura supone la acumulación social de símbolos objetivados (cognitivos, afectivos, morales, valorativos, estéticos, vinculados a los razonamientos cotidianos, etc.), la subjetividad implica un procesamiento de los mismos con un significado singular, lo que puede darse de manera híbrida y heterogénea. 
De ese modo, la forma en que un grupo o colectividad crea y asigna sentidos políticos a la situación en la que se encuentra no es un reflejo mecánico de necesidades históricas ni un producto puro e indiscriminado de la voluntad de los actores, sino que es el resultado de la articulación de modos de significación y prácticas en contextos estructurales.

La categoría de configuración propuesta por el autor (De la Garza, 2001) tiene la potencialidad de destacar el papel que juegan las contradicciones en la subjetivación: se trata de procesos que no son uniformes, lineales ni homogéneos, sino que están atravesados por múltiples tensiones. Así, la emergencia de sentidos políticos en un momento concreto no necesariamente expresa la conformación de una conciencia política claramente definida ni tampoco la existencia de un sujeto específico, ya que ello depende de la mediación que ejercieren las prácticas (que pueden ser fragmentarias y discontinuas) en las que estos se recrean, actualizan y disputan. Hay que pensarlas por lo tanto como configuraciones subjetivas dinámicas y contingentes que van definiéndose en función de las tensiones y acontecimientos emergentes.

Desde esta perspectiva, la propuesta de Retamozo (2007) avanza en la recuperación de la importancia de la historicidad y la proyección, como elementos fundantes de los procesos colectivos de subjetivación: para el autor, los sujetos condensan historicidad no solo porque están atravesados por las experiencias del pasado, sino también porque habitan un presente ("un tiempo dado-dándose") cargado de potencialidades, desde las cuales se definen horizontes posibles de acción (Retamozo, 2007, p. 18). También hace énfasis en que la categoría de subjetividades colectivas debe diferenciarse de la de sujeto social, en tanto remiten a diferentes niveles de abstracción. Mientras la primera refiere a los procesos colectivos de asignación de sentido, la segunda hace hincapié en la fijación y estabilización (aunque sea parcial) de tales elementos en un momento histórico dado, lo que incluye, a su vez, la creación de una identidad colectiva que supone reconocimientos intersubjetivos (Retamozo, 2006, p. 74). Los sujetos tienen un papel fundante en la producción de los diferentes órdenes sociales: las potencialidades implícitas en sus prácticas explican que la realidad social tenga un carácter indeterminado.

También desde una tradición marxista, los aportes realizados por Massimo Modonesi (2010) son otra herramienta potente para el análisis del asunto en cuestión. Desde una perspectiva gramsciana y thompsiana, el autor propone comprender las implicaciones subjetivas de las relaciones de dominación, conflicto y emancipación a partir de la articulación de tres categorías fundamentales: subalternidad, antagonismo y autonomía. Centrando la mirada en las formas en que las clases populares vivencian las experiencias de subordinación, insubordinación y emancipación, el autor sugiere articular dos tipos de análisis: por un lado, un enfoque sincrónico que reconozca cómo en un momento dado se combinan de manera desigual posiciones subalternas, antagonistas y autónomas frente a las situaciones vividas, y, por otro, una perspectiva diacrónica que capte el proceso a través del cual uno de estos elementos predomina sobre los otros, definiendo su particularidad en momentos concretos.

Ambos acercamientos permiten dar cuenta de cómo las subjetividades políticas adquieren forma y especificidad de manera procesual, a partir de la acumulación, procesamiento y sedimentación de prácticas colectivas en el marco de relaciones de poder. Así, los procesos de subjetivación se van forjando y recreando continuamente en función de experiencias de vida atravesadas por el conflicto, lo que supone que adopten formas diversas que pueden ir desde la aceptación pasiva y relativa de la dominación (poder sobre) a su rechazo, crítica e insubordinación (poder contra) hasta la creación de formas de existencia alternativas que pretendan superarla (poder hacer). Es decir, si bien desde esta perspectiva se reconoce que tales procesos son dinámicos y que las subjetividades están en permanente redefinición, la articulación de ambos enfoques (diacrónico y sincrónico) propone realizar cortes en determinados momentos para hacer análisis concreto de situaciones concretas.

Un punto en común que tienen estas perspectivas es la centralidad que adquiere el conflicto capital-trabajo. La experiencia de clase entendida como mediación entre ser social y conciencia (Thompson, 1989) es la referencia central a partir de la cual se configuran las formas subjetivas de existencia. Además, lo que está 
claro es que la clase se va haciendo y conformando en función de las luchas, es decir, que lejos de pensarse como una categoría estática resultado de la explotación económica, esta se va moldeando en relación a las prácticas concretas en las que se inscribe, en las cuales la lógica del capital tropieza siempre con el carácter potencialmente insumiso de la fuerza de trabajo como cuerpo viviente (Virno, 2003). Ello implica que la reflexión en torno a los procesos de subjetivación deba poner la mirada en la trama dinámica de la lucha de clases y las posibilidades de quiebre y ruptura que emergen de tales antagonismos.

Desde nuestro punto de vista, la potencialidad de estos enfoques se enriquecería haciendo hincapié en dos asuntos que han estado generalmente ausentes en las discusiones clásicas del marxismo y que se encuentran en sintonía con las perspectivas críticas aquí recuperadas: el carácter micropolítico y no necesariamente lógicoracional de las disputas y la crítica a la idea de un sujeto político homogéneo y trascendental. Asumir ambas exigencias requeriría desterrar tres premisas arraigadas dentro del marxismo ortodoxo: la subestimación de la dimensión afectiva de la conducta humana, la sobrevaloración de la lucha de clases como único motor de la historia, y la creencia en un sujeto abstracto (clase obrera o proletariado) portador de luchas emancipadoras con una conciencia política definida.

$\mathrm{Al}$ respecto, la perspectiva posestructuralista que se abre con Foucault, Deleuze y Guattari, aporta herramientas claves para dar cuenta de la relevancia que tienen los afectos, deseos y pasiones en la definición de los modos subjetivos de existencia. No se trata de pensar la construcción política a partir de grandes eventos agenciantes, sino de reconocer la especificidad de los sucesos pequeños, aquellas singularidades que resultan del juego azaroso de relaciones de fuerza, con sus múltiples posibilidades de irrupción y desplazamiento. Así, la categoría de acontecimiento resulta crucial para abordar las prácticas colectivas de resistencia en tanto muestra "lo que una época tiene de intolerable, pero también hace emerger nuevas posibilidades de vida" (Lazzarato, 2006, p. 44).

Desde esta mirada no hay que entender la conformación de sujetos políticos como la culminación de un proceso, sino como un "devenir inacabado" (Tassin, 2012, p. 37): una reconstrucción permanente en la que se construyen fuerzas activas con potencialidades diversas en función de las experiencias y prácticas. Es decir, antes que hablar de sujeto como un estado al que se llega en un momento dado, habría que pensar en procesos que nunca adquieren una forma fija y que tampoco pueden anticiparse, ya que son flujos indeterminados, dependientes de relaciones y circunstancias externas y discontinuas.

Desde una mirada ranceriana (Ranciére, 1996), se trata de procesos de desidentificación caracterizados por una dinámica disruptiva que escapa a cualquier intento de clasificación o localización: el subjetivarse supone composiciones de fuerzas que no solo no cristalizan en formas puras y acabadas, sino que tampoco son reconocibles ni predecibles. La construcción de subjetividades políticas refiere así a procesos de singularización situados (anclados a una espacialidad y temporalidad dada) que suponen siempre una relación con una otredad, es decir, se constituyen en función de la alteridad y conllevan la negación de las lógicas identitarias hegemónicas.

En tales prácticas se pone en juego el disenso con los mecanismos de asignación de sentido previos, a la vez que se afirman potencialidades plurales relativamente novedosas. Ahora bien, ello no significa que las grietas sean totales, ya que son procesos complejos con múltiples contradicciones: la emergencia de sentidos disruptivos no supone un quiebre absoluto con lo heredado, sino que se combinan la repetición con la creación de formas diversas de existencia (Martínez y Cubides, 2012). Es decir, las subjetivaciones no devienen necesariamente en agenciamientos creadores, ya que fuerzas reactivas (la repetición, el contagio o la imitación) pueden limitar la posibilidad de invención y anular horizontes de autoafirmación colectiva (Piedrahita, 2012). La singularidad de dichos procesos confirma que la producción de sentidos políticos en relación al trabajo está abierta a la metamorfosis de las prácticas y afecciones que emergen con ellas. 


\section{IMPLICACIONES EPISTEMOMETODOLÓGICAS}

Los problemas planteados tienen implicaciones epistemológicas con repercusiones concretas en términos metodológicos. Un aspecto central a destacar tiene que ver con las formas en que se construye el dato y las estrategias concretas que nos damos para captarlo y analizarlo en toda su complejidad. En lo siguiente, esbozamos algunos criterios que consideramos claves al respecto.

\subsection{La construcción del dato}

Uno de los principales consensos en las corrientes críticas al positivismo es la idea de que el dato no existe por sí mismo, sino que se conquista y construye: ningún objeto habla por sí solo si no se le interroga (Bourdieu y Passeron, 2008). Así como los hechos empíricos no están dados, tampoco son creación pura de la persona que investiga, sino que se construyen en la relación del sujeto con el objeto. Esto supone una labor de interpretación que pone en cuestión la concepción positivista de la investigación como una práctica desubjetivada. Es decir, no existe el dato en forma pura, sino que este es inevitablemente resultado de la articulación de elementos objetivos y subjetivos, lo que cuestiona e invalida el postulado positivista de la neutralidad valorativa. Con ello no solo se reconoce la historicidad de todo objeto, sino también que la condición de posibilidad de su conocimiento es histórica. Esto no sólo implica la no universalidad de los conceptos y leyes, sino también el reconocimiento del sujeto en dicho proceso.

En América Latina, el pensamiento de Hugo Zemelman da inicio a una tradición epistémica crítica que plantea la necesidad de reconocer el papel que tienen los sujetos en la construcción y delimitación de los horizontes posibles de acción, lo que supone que la realidad objetiva no está determinada (no existe un dato preestablecido), sino condicionada a la potencialidad de los sujetos y sus prácticas (Zemelman, 1987). En esta misma línea, De la Garza (2018) señala que el dato sufre tensiones de carácter lógico e histórico: no solo está condicionado por la teoría y los instrumentos que se adopten, sino que siempre está mediado por el lenguaje y la subjetividad de la persona investigadora, quien tiene un papel activo en la construcción del mismo y no es simple receptora de "lo dado". Es decir, el dato empírico es una forma de relación del objeto con el sujeto en articulación dinámica con otros niveles de realidad más allá de las prácticas significativas.

En sintonía con ello, la noción de subjetividad epistémica de Retamozo (2007) plantea que la producción de conocimiento se da siempre desde un sujeto que tiene una determinada concepción de la realidad (sea consciente o no de ella), razón por la cual no solo es necesario reconocer que la subjetividad es la condición de posibilidad de la objetividad científica, sino también que toda investigación requiere de la construcción de una postura epistémica, es decir, de un sujeto que se sitúe "en y ante las circunstancias y construya una postura frente a un horizonte de conocimientos posibles de construir" (Retamozo, 2007, p. 5). Tal posicionamiento supone a su vez la asunción de actitudes ético-políticas coherentes con la postura asumida. Desde este enfoque, se considera que tanto la voluntad como la conciencia son elementos claves en la construcción de una subjetividad epistémica crítica (Retamozo, 2007, p. 11).

A partir de los supuestos de la epistemología crítica, en esta investigación hablamos del dato "doblemente subjetivo", para hacer referencia a aquel que trata la cuestión de la subjetividad en sentido estricto. Es decir, si bien reconocemos que no existe dato que no esté mediado por la subjetividad, en el caso que nos compete, este se encuentra embebido de la misma, dado que los procesos colectivos de asignación de sentido constituyen el objeto principal de reflexión y análisis. Lo interesante a destacar es que la naturaleza doblemente subjetiva del problema en cuestión complejiza la discusión metodológica, sobre todo si se tienen en cuenta las siguientes implicaciones:

a) Las subjetividades (sean individuales o colectivas) tienen un carácter social ineludible: todo proceso de asignación de sentidos, sea personal o colectivo, se enmarca en condiciones materiales y sociales de existencia, 
es decir, no puede explicarse sino en vinculación con las prácticas de las que surge, las interacciones en las que se recrea, y las estructuras sociales y relaciones de fuerzas que lo condicionan. La inclusión de las tramas simbólicas dentro de la tríada estructuras-subjetividades-acciones (De la Garza, 2001) rompe con el dualismo subjetivo-objetivo en las ciencias sociales, reconociendo que, si bien los significados son creados en interacciones cotidianas, también las exceden. Esto ocurre tanto en el caso de que refieran a objetivaciones materiales y simbólicas heredadas culturalmente, como en el caso que traten de saberes prácticos, de los cuales no se tiene un conocimiento reflexivo en la vida cotidiana pero que sin embargo inciden en las formas de existencia individuales o colectivas.

b) Si bien las subjetividades se construyen en situaciones específicas, no se agotan en ellas. Los procesos de significación se alimentan de interacciones y estructuras objetivas y simbólicas en múltiples espaciotemporalidades. Así, los procesos de subjetivación se arraigan en un presente que recupera historias y memorias pasadas, al mismo tiempo que se proyectan hacia posibles horizontes futuros, excediendo así las particularidades espaciales y temporales en las que fueron creadas. En ese sentido, la dicotomía micro-macro deja de tener efecto, dado que las formas subjetivas de existencia se alimentan tanto de disposiciones sociales y culturales acumuladas históricamente, como de las resignificaciones que se dan en las experiencias cotidianas de vida. Es decir, el proceso subjetivo está atravesado por múltiples tensiones de diversos ámbitos y niveles de realidad que pueden no ser conscientes para los sujetos y que sin embargo influyen en el modo de significar y también en la toma de decisiones.

c) Aun cuando se exterioricen en prácticas, gestos y discursos que pueden ser interpretados públicamente, las subjetividades no siempre son transparentes, así como tampoco se reducen a motivos de la acción, conductas manifiestas o estructuras psicológicas. Las intenciones, gustos, preferencias o expectativas registradas por los actores se combinan con afectos, deseos, conocimientos, creencias, valores y lógicas de razonamiento práctico que no necesariamente son registrados ni manifestados a través del lenguaje en un testimonio o relato público. Es decir, no son procesos del todo conscientes, en tanto es imposible que los sujetos tengan conocimiento de todas las objetivaciones materiales y simbólicas que influyen en sus procesos de asignación de sentidos. Asimismo, como plantea Piedrahita (2015), lo subjetivo no se produce a través del lenguaje sino del acontecimiento, lo que sin dudas rebasa cualquier acto comunicativo. El carácter latente $\mathrm{u}$ oculto que pueden tener tales significaciones genera que su discernimiento no siempre sea claro y preciso.

d) La producción subjetiva en cada situación concreta es diversa y heterogénea. Aun cuando ciertas experiencias (de clase, género o raza) condicionan el modo de significar la realidad, las posibilidades que adopten los sentidos colectivos son múltiples y en direcciones no definidas. Es decir, a pesar de que las estructuras simbólicas dominantes inciden en los modos de significación, los procesos de creación subjetiva no son uniformes, sino que adquieren devenires propios en cada caso, y existen siempre posibilidades de transformación y ruptura de los sentidos hegemónicos. Ahora bien, que la producción subjetiva dependa de situaciones concretas no quiere decir que sea indiscriminada ni absolutamente contingente, ya que los condicionamientos económicos, sociales y culturales delimitan ámbitos de posibilidades (De la Garza, 2001) en relación a aquello que puede o no ser significativo en cada momento específico.

e) Las tramas de significación no son necesariamente coherentes, aunque tampoco del todo caóticas: las subjetividades se componen de fuerzas activas y reactivas que pueden entrar en tensión. Lejos de tener una lógica homogénea, dichas urdimbres se entretejen en forma inconsistente, por lo que pueden existir relaciones de primacía, subordinación o determinación entre los diferentes códigos que la componen (por ejemplo, que prime más un criterio moral que normativo, o uno emotivo más que cognitivo). A su vez, los significados que se crean no tienen por qué tener correspondencia funcional o causal entre sí; la articulación de códigos puede tener diferentes niveles de fragmentación, hibridación y mixtura, y es esto lo que impulsa la acción en una dirección dada.

f) Si bien los significados pueden adquirir cierta estabilidad en una espacialidad y temporalidad dada, los procesos de asignación de sentidos se caracterizan por su dinamismo permanente. Aunque las subjetividades 
antecedan a las prácticas, se modifican y reconstruyen con ellas, y también más allá de las mismas, en tanto pueden objetivarse. Reconocer ello implica asumir que las subjetividades se van tejiendo en la medida en que se vivencian y transitan experiencias concretas, con la posibilidad de que en las prácticas se generen nuevas sensibilidades y formas de significación. Ahora bien, el desafío es descubrir no solo cómo ciertos códigos pueden resignificarse en las interacciones, sino también la posibilidad de que en un momento dado estos se consoliden e institucionalicen en una modalidad específica, aunque claramente no se trate de formas fijas ni absolutas.

Estos elementos son relevantes porque ponen en cuestionamiento tanto los criterios positivistas como hermenéuticos de construcción del dato. Las subjetividades no solo no están ahí como "hechos dados" a ser observados, sino que tampoco pueden reconocerse a través de inspecciones profundas al "mundo interno" de las personas; más bien, su abordaje requiere una reconstrucción en el plano del pensamiento que pueda desentrañar los diferentes niveles de realidad que las atraviesan, y que incluya aquellos condicionamientos objetivos y subjetivos que pudieren no ser conscientes, y sin embargo, inciden en sus prácticas y sentidos.

Si entendemos las prácticas políticas como aquellas acciones colectivas que en una situación concreta suponen una transformación o alteración de las condiciones de existencia (independientemente de su alcance, eficacia, duración y grado de conciencia o espontaneidad), el universo de posibilidades se amplía. Ya no se trata solamente de las acciones que conllevan una disputa explícita al Estado, sino también de aquellas expresiones de resistencia que, aun manifestándose en formas disimuladas, ocultas y anónimas, suponen una impugnación al orden dominante. En ese sentido, habría que considerar no solo las prácticas voluntarias (relativamente conscientes) e involuntarias (inercias, vicios y rutinas) (Modonesi, 2016), sino también todas aquellas manifestaciones de insubordinación colectiva que se presentan de manera encubierta: desobediencias, boicots, burlas, ironías, humor, abulia, pasividad, etc. En cualquiera de estos casos, el análisis de los relatos emitidos por los actores permite dar cuenta de la capacidad de enunciación, sensibilización y reflexividad sobre las prácticas, entendiendo que estas rebasan siempre a los discursos por lo que el dato nunca se reduce a lo expresado verbalmente. Ampliar la mirada a otras manifestaciones posibles (latentes, ocultas, anónimas y silenciadas) nos permite aprehender las experiencias subjetivas en su complejidad y en sus grados diversos de visibilidad/invisibilidad.

\subsection{La estrategia metodológica}

El carácter impredecible de los hechos subjetivos nos lleva a plantear la necesidad de asumir un enfoque antipositivista con la suficiente flexibilidad para captar los procesos en sus devenires concretos, teniendo en cuenta que siempre existe la posibilidad de que emerjan sensibilidades cuya forma no haya sido teorizada aún. Esto requiere desechar todo tipo de explicación deductiva y construir alternativas que rompan con la formulación de hipótesis a ser demostradas empíricamente; los procesos de subjetivación no solo no pueden anticiparse sino que tampoco son fácilmente reconocibles. Por lo tanto, no se trata de comprobar la presencia o no de ciertos códigos como resultado de condiciones objetivas dadas, sino de abrir la posibilidad a la emergencia de formas múltiples de significación que puedan entrar en tensión. El objetivo no es verificar que se den cierto tipo de subjetividades, sino crear conocimiento específico acerca de las formas subjetivas de existencia en un momento dado, descubriendo qué elementos específicos intervienen en el proceso de significación y cómo se articulan para producir dicha configuración y no otra. Para ello se requiere un camino metodológico abierto a la reconstrucción de estos devenires entendiendo que son procesos que se están dando en el presente, por lo que no pueden captarse a través de un pensamiento deductivo sino de una mirada minuciosa hacia aquellas transformaciones que van siendo potencialmente viables en la fluidez de las prácticas.

La metodología configuracionista (De la Garza, 2018), basada en la descripción articulada (Zemelman, 1987), sugiere no partir de hipótesis sino de un planteo amplio y lo suficientemente abierto para descubrir 
las múltiples determinaciones (objetivas y subjetivas, coyunturales y estructurales) que atraviesan la situación concreta. Se comienza definiendo ejes problemáticos a partir de los cuales se delimitan (de manera tentativa) ámbitos de relaciones sociales que pueden estar incidiendo en la subjetivación (trabajo, familia, género, etc.). Luego, se plantea la creación de categorías ordenadoras que orienten la búsqueda de tales relaciones sin pretender ningún tipo de correspondencia lógica entre la teoría y la empiria. Más bien, se propone que sean guías para dar cuenta de las estructuras, subjetividades y acciones que entran en juego. La construcción de tales conceptos se va haciendo a partir de la teoría acumulada y la exploración empírica, con la posibilidad de que sean reformulados, ya sea por nuevas problematizaciones, ajustes de diseño, o porque la propia realidad los invalide. Es decir, no se pretende comprobar o verificar su contenido, sino más bien utilizarlos para interrogar a un objeto que está en continuo movimiento. Por ello mismo no se busca una exactitud lógica y deductiva en la relación entre las categorías, sus dimensiones e indicadores: las opciones pueden ser múltiples y la elección de una u otra va a depender de los hallazgos de campo.

Modonesi también plantea el uso de "conceptos-horizontes" (Svampa, 2015, p. 17) para el acercamiento a la realidad empírica. Subalternidad, antagonismo y autonomía constituyen la tríada conceptual que permite captar las formas y dinámicas que adquieren los procesos de subjetivación política. Tal entramado surge con la intención de construir un andamiaje teórico para el abordaje de las experiencias de dominación, conflicto y emancipación en los movimientos sociopolíticos (Modonesi, 2010). La idea es que en un primer momento estos conceptos se utilicen en forma separada para poder distinguir la especificidad de cada configuración, y luego se homologuen y complementen para dar cuenta de los traslapes que atraviesan estas experiencias. La descomposición analítica de dichas categorías supone definir para cada una de estas experiencias una determinada posición ante las relaciones de dominación, ciertos tipos de acciones con proyectos y resultados, de modo tal de construir indicadores que permitan medir las formas, grados e intensidades con la que estas dimensiones se presentan.

Respecto a las primeras, la subalternidad supone un "adentro" (aceptación relativa y disensos puntuales y esporádicos); el antagonismo, un "contra” (impugnación y confrontación), y la autonomía, un "más allá" (negación y superación). Las acciones que las caracterizan, en forma respectiva, son la pasividad y resistencia defensiva, la lucha y rebelión ofensiva, y la afirmación y autodeterminación, lo que da como resultado la reproducción y renegociación de un poder sobre, la formación de un poder contra y el establecimiento de un poder hacer. Se propone, a su vez, que estos criterios de diferenciación se visualicen en cuatro ámbitos de prácticas colectivas: politización (agregación y enunciación), organización (participación y deliberación), movilización (manifestación y difusión), y realización (articulación, negociación y autonomización) (Modonesi, 2016). La articulación y el cruce de estas dimensiones orientan y ordenan el abordaje del fenómeno en cuestión.

A diferencia de ambas estrategias, Claudia Piedrahita $(2013,2015)$ propone abrir el camino a un pensar crítico que no parta de la revisión de teoría acumulada, sino de la propia experimentación en relación a los procesos estudiados. Sugiere cartografiar los acontecimientos emergentes en el ámbito micropolítico poniendo la mirada en las divergencias que transcurren de manera circunstancial, para descubrir las fuerzas que las impulsan (su carácter activo o reactivo) y sus devenires políticos sin pretender encontrar relaciones de causa-efecto. Ello permite no solo reconocer lo que va sucediendo, sino también experimentar con los sentidos que se van creando, para hacer visibles los estados afectivos que desbordan los límites de lo representado a través del lenguaje. Desde esta postura, se busca un pensar crítico (pensamiento dislocado) que enfoque la mirada en el flujo e intensidad de lo que va dándose, reconociendo los afectos involucrados, con sus conexiones, límites y mutaciones, haciendo visible lo indecible a partir de la propia experimentación.

Sea uno u otro caso, la implementación de dichas estrategias requiere que el diseño de las herramientas de producción de la información empírica también sea abierto y flexible. La propia complejidad del dato sugiere una combinación creativa de técnicas cualitativas. Observaciones directas y participantes, entrevistas etnográficas, relatos de vida, grupos de discusión, performances artísticas (teatro, parodia, fotografía, danza, 
etc.) permiten abordar las experiencias subjetivas en sus diversas expresiones y sus diferentes grados de visibilidad e invisibilidad. Por otro lado, la revisión documental y hemerográfica puede servir para la reconstrucción de los contextos en los que emergen las tramas subjetivas. Lejos de dispersar la mirada, el cruce de fuentes sirve para validar la veracidad de los hallazgos, sopesar el valor de los mismos y ejercer una vigilancia epistemológica crítica respecto a los sentidos creados, sobre todo si se tiene en cuenta la doble hermenéutica que atraviesa la práctica investigativa.

También es importante señalar que la aplicación de dichas técnicas no se da en forma autómata, ya que el proceso de investigación es una experiencia dialógica (no solo verbal sino también corporal) en la que se ponen en juego sensibilidades y racionalidades tanto por parte de quienes investigan como de quienes son estudiados. Reconocer los encuentros, desencuentros ydistancias entre unos y otros no significa adherir a la idea de un relativismo subjetivo, sino entender que la producción de conocimientos supone compromisos desde terrenos ético-políticos en los que la neutralidad se torna imposible, aunque ello no significa que todo abordaje pueda ser legítimo en cualquier circunstancia. Las imágenes de la "investigadora impostora" (Bonvillani, 2013, p. 91) y de la "traficante de experiencias" (Bonvillani, 2013, p. 94) descritas por la autora dan cuenta de las tensiones y disputas a las que está sujeta la práctica investigativa. No se trata por lo tanto de pensar la objetividad como ausencia valorativa, sino de asumir el desafío de construir conocimiento que se sustente en prácticas concretas y que pueda ser reconocido y validado desde puntos de vista diversos. Como plantea Zemelman (1987), no hay objetividades que sean ajenas a los sujetos, pero ello no quiere decir que la realidad se reduzca a dichas voluntades, dado que las prácticas están delimitadas por horizontes de acción objetivamente viables.

\subsection{El análisis: descubrimiento y creación de conocimiento}

En el estudio de los procesos de subjetivación política podemos diferenciar dos estrategias analíticas íntimamente relacionadas: la construcción de la configuración subjetiva en un momento dado (sincrónico) y el análisis de su evolución a lo largo del tiempo (diacrónico). La articulación y entrecruzamiento de ambas dimensiones constituye uno de los grandes desafíos de la investigación.

Desde un enfoque configuracionista se trata de reconstruir los códigos que intervienen en el proceso de significación y la forma en que se articulan en una situación concreta. Para reconocerlos creemos que puede ser útil visualizar distintos momentos dentro del proceso subjetivo, aunque no se trate de etapas diferenciadas en la realidad, sino de un ejercicio de discernimiento propiamente analítico. Entre éstos destacamos:

1) Lo que antecede al "hecho": la resignificación de códigos como resultado de experiencias comunes;

2) El "hecho" en sí mismo: la creación colectiva de sentido en relación a una situación particular dada;

3) Su derivación: las mutaciones de tales sentidos al calor de la acción colectiva.

El reconocimiento de estas instancias va de la mano de una mirada minuciosa que pueda dar cuenta de cómo ciertos códigos pueden transformarse y/o activarse a la luz de las experiencias; cómo se articulan y asimilan las contradicciones, y qué es lo que permite que ciertos códigos predominen frente a otros para definir así el carácter de la configuración. Es decir, si consideramos que los sentidos están modificándose en forma continua, dichos enfoques requieren ser complementados con una perspectiva diacrónica que pueda reconocer su evolución en un determinado lapso de tiempo, lo que implica poner atención a los sucesos que van detonando otras posibilidades de existencia, tanto a nivel de los afectos como de los deseos, entendiendo que no se trata de procesos ascendentes sino de flujos de fuerzas en constante movimiento.

Desde la perspectiva de Modonesi, el abordaje sincrónico debe poder dar cuenta de la forma específica en la que se combinan, en un espacio y tiempo dados, experiencias de subalternidad, antagonismo y autonomía. A partir de la idea de que dicha articulación se da en forma tensa y desigual, se busca reconocer cuál de estas experiencias es la que predomina en un momento dado (sopesando el valor de cada dimensión en relación a las otras), registrando las imbricaciones que se dan entre las mismas en función de su coexistencia simultánea 
y complementaria. Con el afán de distinguirlas se propone diferenciarlas según ámbitos de surgimiento (dominación, conflicto o liberación), modalidad (subordinación, insubordinación o emancipación), formas de expresión (aceptación y resistencia, impugnación y lucha, o negación y superación), alcances (dentro de, contra o más allá) y proyecciones (negociación del poder sobre, creación de un poder contra, creación de un poder hacer) (Modonesi, 2010, p. 163).

Con tales criterios no se pretende establecer tipologías sino dar cuenta del modo en que coexisten y se combinan en un momento dado, para identificar (en forma análoga a un registro fotográfico) cómo una de estas experiencias sobredetermina, estructura y define la configuración subjetiva, y reconocer no solo sus elementos centrales sino también los subordinados. Ahora bien, que exista un predominio de una de ellas no quiere decir que se genere una homogeneización, ya que son procesos plagados de tensiones, las cuales activan rupturas en la asignación de sentidos. Justamente es la mirada diacrónica (propia del plano cinematográfico) la que permite dar cuenta de las mutaciones a lo largo del tiempo e identificar secuencias posibles de tales procesos (avances lineales, estancamientos, reflujos u oscilaciones), lo que posibilita construir periodizaciones en relación a los ciclos de lucha y movilización social. Reconstruir la configuración dinámica de hechos y relaciones que tornan posible el pasaje de una experiencia a otra (por ejemplo, de la subordinación al antagonismo o del antagonismo a la autonomía) constituye una de las principales apuestas del análisis empírico.

\section{INTERPELANDO AL CASO: ENSAYANDO ARTICULACIONES POSIBLES}

Para ejemplificar las propuestas descritas, retomamos una pesquisa en la que adoptamos la perspectiva configuracionista de Enrique De la Garza para analizar dicha problemática en un call center de la Ciudad de México, caso que había sido expuesto en una publicación anterior (Montarcé, 2015). La presentación de los resultados, con sus alcances y limitaciones, nos sirve hoy como disparador para encarar una reflexión crítica de la metodología en cuestión e ilustrar posibles articulaciones entre los enfoques tratados en este documento.

\subsection{La “cocina” de la investigación}

Uno de los principales objetivos de la investigación mencionada fue analizar el impacto subjetivo que tuvo la experiencia de acción y organización colectiva en un call center en el que se dio un proceso de sindicalización genuino y exitoso. Nos referimos a Tecmarketing, compañía de un corporativo de origen mexicano (Grupo Telmex) líder en telecomunicaciones, que ofrece servicios de atención al cliente, soporte técnico y venta de productos a filiales del mismo corporativo, así como al sector privado y paraestatal. La empresa inició operaciones en 1997 con un esquema de amplia flexibilidad y unilateralidad que implicaba condiciones precarias, salarios bajos, fuerte inestabilidad y alta rotación. En 1998 se dio un movimiento de trabajadores/as que tuvo como resultado la formación de una sección sindical (159) dentro del Sindicato de Telefonistas de la República Mexicana (STRM), el cual obtuvo la titularidad del contrato colectivo en febrero de 1999. El caso es paradigmático dentro del ámbito de los call centers, por tratarse de una empresa que mutó de un esquema de regulación con amplia unilateralidad a otro regido por la negociación colectiva, lo que generó cambios significativos no solo en las condiciones de empleo sino también en las dinámicas de participación de los/as trabajadores/as. Dicho tránsito no fue mecánico ni lineal, sino atravesado por tensiones de diferente índole, con repercusiones concretas en términos subjetivos.

En este apartado nos interesa destacar cómo fuimos construyendo los datos en relación a los procesos de subjetivación que se dieron al calor de la experiencia sindical analizada. En primer lugar, es importante aclarar que no nos interesó explorar el impacto que tuvo la experiencia organizativa en tal o cual trabajador/a, sino analizar sus efectos en las prácticas colectivas. Es decir, no tratamos individualidades, sino que la mira siempre 
estuvo puesta en los procesos colectivos de politización. En segundo lugar, explicitar que analizamos las subjetividades en tanto configuraciones, lo que supuso reconstruir en cada momento cuáles eran los códigos culturales (emotivos, cognitivos, estéticos, del razonamiento cotidiano, etc.) que influían en los significados que se iban construyendo en torno a la experiencia organizativa. Finalmente, señalar que nos interesó analizar las transformaciones que sufrieron dichas configuraciones como resultado de los procesos señalados, es decir, que hubo un interés especial en desentrañar las mutaciones que se dieron en el ámbito de la subjetividad colectiva como efecto de la experiencia sindical.

En relación a la estrategia metodológica, asumimos los supuestos configuracionistas ya señalados, reconociendo la inutilidad de un planteamiento hipotético: no se trataba de comprobar la existencia o no de ciertos códigos como resultado de condiciones objetivas dadas, sino de dejar abierta la posibilidad a la emergencia de formas múltiples de significación que pudieran rebasar lo ya teorizado. En ese sentido, la estrategia no tuvo como objetivo verificar, sino reconstruir teóricamente los códigos existentes, la forma en que éstos se articularon y las mutaciones que fueron dándose en dicha configuración como resultado de la experiencia organizativa. En términos concretos, ello implicó reconstruir cómo ciertos códigos se transformaron a la luz de las experiencias vividas, cómo algunos hechos claves permitieron la activación de otros códigos que se mantenían latentes, las formas en que estos se articularon, y las mutaciones que se dieron a lo largo del tiempo. Desentrañar este dinamismo fue fundamental para dar cuenta de los desplazamientos producidos en las subjetividades colectivas como resultado de las experiencias transitadas.

A partir de la idea de que las experiencias subjetivas surgen de múltiples determinaciones, adoptamos una estrategia cualitativa basada en una articulación de técnicas (entrevistas individuales y colectivas, observación directa y participante, y amplia revisión documental) que nos permitieran contrastar las narrativas de los actores (testimonios personales, relatos colectivos y discursos públicos) con las interacciones en las que se validaban los sentidos reconstruidos. Es decir, prácticas y discursos, con toda su singularidad y complejidad, son las dos unidades de análisis que, en forma articulada y simultánea, nos permitieron reconstruir los procesos de movilización subjetiva que se dieron en relación a la experiencia sindical.

Para analizar dichos procesos, un primer paso fundamental fue identificar los códigos culturales (emotivos, cognitivos, morales, estéticos y del razonamiento cotidiano) que atravesaban las experiencias de los/as trabajadores/as del call center, y cómo estos incidían no solo en las valoraciones que ellos/as hacían de su actividad laboral y sus condiciones de empleo, sino también en la inclinación a la acción y organización colectiva. Es decir, pusimos la mirada en las disposiciones afectivas, cognitivas, morales, estéticas y del sentido común que actuaron (junto con prácticas e interacciones de otros niveles de realidad) como desencadenantes de procesos organizativos de carácter sindical. Para captarlas, prestamos atención a las valoraciones y expectativas que se manifestaban (de manera discursiva y en las propias interacciones) en relación a la actividad laboral. Las relaciones cotidianas en los espacios de trabajo y en los ámbitos sindicales nos daban pistas del modo en que los/as trabajadores/as resignificaban el cúmulo de condicionamientos y experiencias comunes que les afectaban, para crear sentidos a su situación concreta. Asimismo, exploramos cómo aquello que era significativo para ellos/as se articulaba con estructuras, habitus y prácticas que no necesariamente podían reconocer, pero que sin embargo tuvieron relevancia en la acción y organización colectiva. Finalmente, nos interesó rastrear las mutaciones de tales sentidos al calor de la propia dinámica organizativa, identificando momentos que fueron claves para el desplazamiento y la reorientación de los sentidos colectivos.

\subsection{Los hallazgos: de la aceptación pasiva a la estabilidad tensa}

Una de las inquietudes centrales que surgió en el proceso de investigación fue explorar cómo el consentimiento pasivo con las condiciones de empleo por parte de los/as trabajadores/as (que no significaba ausencia de inconformidades) se convirtió, en un momento dado, en una voluntad colectiva de cambio, 
y, además, cuál fue el curso que fue tomando dicha movilización subjetiva a lo largo de la experiencia organizativa. Al respecto, encontramos que dichas transformaciones fueron resultado de procesos complejos, que no tuvieron un desarrollo unívoco sino contradictorio y tenso.

La información que se presenta corresponde a acontecimientos que se dieron a partir de 1999, momento en el que inició el proceso de sindicalización (ver cronología del conflicto en Anexos). Sin embargo, el "antes" y el "después" se plantean con un fin estrictamente expositivo y analítico, ya que la fluidez y el devenir de dichos sucesos hace que sea imposible delimitarlos de manera precisa.

Las condiciones previas a la sindicalización generaban amplio descontento: despidos injustificados, bajos salarios, precariedad edilicia, incumplimiento en el pago de horas extras, favoritismos en los mecanismos de ascenso, etc. Ahora bien, esas inconformidades se mezclaban con cierto agrado por la informalidad y flexibilidad y por un gusto por el ambiente juvenil existente, lo que explicaba la voluntad de quedarse "un tiempo" en la empresa. En ese momento se aceptaban pasivamente tales condiciones, lo que se explicaba por la precariedad del mercado laboral y la falta de oportunidades asociadas a ello, pero también por un razonamiento pragmático de transitoriedad (aguantaban porque lo veían como algo pasajero). Existía un sentimiento de indignación con la empresa pero no tenían expectativas de permanencia; además, el descontento con las condiciones se compensaba con el agrado que les provocaba la informalidad, el ambiente juvenil y los lazos afectivos. Es decir, existían contradicciones entre estos elementos, pero el código que finalmente primaba era el consentimiento con el orden productivo.

Este razonamiento va a transformarse de manera relevante con la sindicalización, no porque dejara de existir aprobación sino porque sus bases de sustentación fueron diferentes. La acumulación de agravios, sumada al activismo de un grupo de trabajadores/as y al respaldo de una estructura sindical ya existente, generó las condiciones para la conformación de una voluntad colectiva que pudo disputar materialidades y sentidos al orden gerencial. Como resultado de ello, con el tiempo se logró estabilidad y bilateralidad en la regulación de las condiciones de empleo, a la vez que se fue gestando una nueva institucionalidad que alteró las relaciones de fuerzas, lo que permitió cierta redistribución del poder entre la gerencia y los/as trabajadores/ as. La vivencia de este proceso incidió en sus prácticas, sensibilidades y formas de conciencia, y permitió la creación de una subjetividad política ambigua y contradictoria.

La conquista de la estabilidad laboral tuvo efectos paradójicos a lo largo del tiempo. El deseo de preservación de lo adquirido y el miedo a perder dichas condiciones generó cierta desmovilización y en ocasiones frenó los intentos de radicalización. Un claro ejemplo de ello fue la huelga realizada en febrero de 2008. Lo paradójico de esta vivencia no sólo fue la imprevisibilidad con la que surgió (se dio de manera relativamente espontánea), sino sus consecuencias. El principal aprendizaje fue la revalorización del trabajo y la necesidad de cuidar lo adquirido, y esto, con el tiempo, se tradujo en un aprendizaje colectivo muy arraigado en la base de trabajadores/as: no desear que la experiencia de la huelga se repita. Además, fue predominando un razonamiento de tipo pragmático e instrumental (manifestado en la adopción e internalización de una cultura productivista), que se combinaba por un lado con un sentimiento de frustración tanto por la monotonía de la actividad como por el hecho de no contar con expectativas de profesionalización (dicha ocupación no era la proyección deseada), y, por otro, con un cierto agrado por la certidumbre en el empleo, la permisividad de la empresa, los beneficios económicos adquiridos y los vínculos construidos con sus pares. A su vez, la bilateralidad y apertura al diálogo que la empresa manifestó a lo largo de estos años fomentó la concertación y el autodisciplinamiento con la producción, aunque no dejaron de darse transgresiones individuales y deseos de romper dicha conciliación. Es decir, si bien la estabilidad dotó de sentido al empleo, también activó significaciones y prácticas contradictorias, lo que finalmente incidió en el apaciguamiento de sus prácticas políticas.

Algo similar sucedió en relación a la experiencia de sindicalización: aun cuando sensibilizó y permitió la creación de una conciencia política crítica, ello no implicó mayor radicalización. Si en un primer momento se gestaron afectos, sensibilidades y conciencias de corte clasista, con el tiempo fueron mutando hacia actitudes 
concertadoras justificadas como "realistas" en el contexto económico. En síntesis, la articulación de los elementos mencionados compensó las insatisfacciones y promovió una práctica conciliadora, aunque no por ello menos consciente de su carácter de clase. Estos procesos no tienen que entenderse como actos voluntaristas aislados, sino como formas subjetivas de existencia que se fueron definiendo al calor de las acciones colectivas emprendidas.

El siguiente esquema sintetiza los desplazamientos subjetivos descritos:

Esquema 1: Los desplazamientos subjetivos: de la aceptación pasiva a la estabilidad tensa.

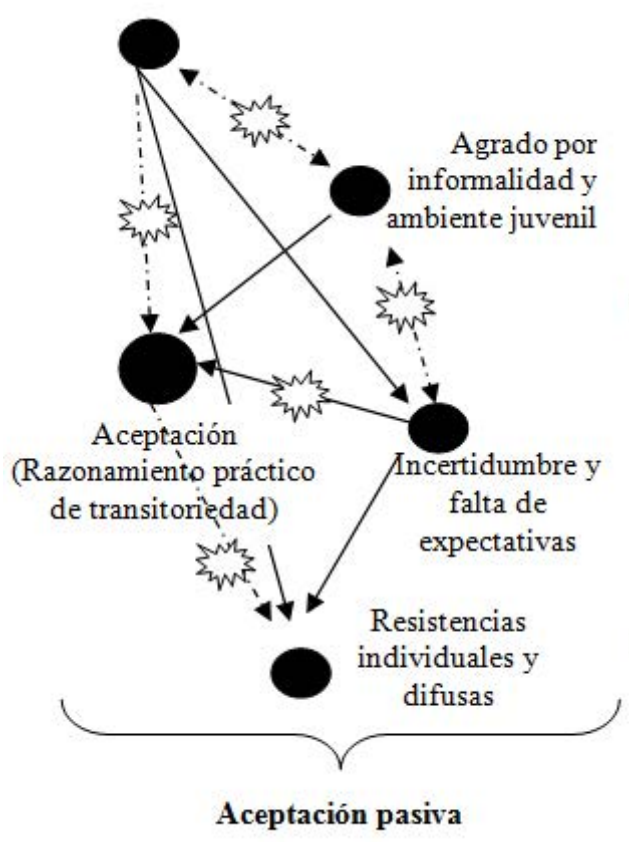

Referencias:

$\longrightarrow$ Relación causal

$\longleftrightarrow$ Relación funcional

$\leftrightarrow \cdots \rightarrow$ Relación laxa

Discontinuidad (sin flecha).

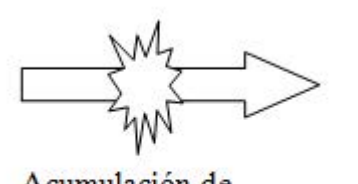

Acumulación de agravios

Voluntad de cambio de una "minoría activa".

Negociación entre cúpulas

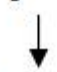

Proceso de sindicalización exitoso

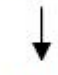

Huelga como momento crítico

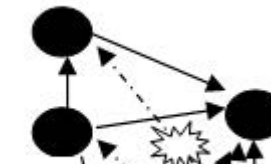

Aceptación

(razonamiento pragmático e instrumental, conocimiento de
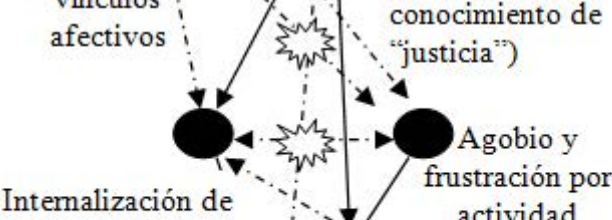
cultura productivista

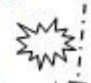
actividad

\section{Confianza}

delegativa en sus

Resistencias

individuales y difusas

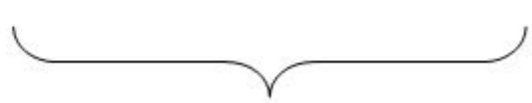

Estabilidad tensa

(como condicionante objetivo y estructura de significación)

\section{$\sum_{m w^{3}}^{m}$ Contradicciones}

Fuente: Elaboración propia (publicado en Montarcé, 2015, p. 256).

Si analizamos estos hechos desde una lectura modonesiana, los hallazgos se potencian. Si bien la subordinación que prevalecía antes de que se diera la sindicalización (aceptación combinada con resistencias individuales y difusas) se modificó a lo largo del tiempo, hecho que dio lugar a la creación de una postura impugnatoria (manifestada en la cristalización de una voluntad de cambio) y a la consolidación de una estructura propia con objetivos reivindicativos, tales acontecimientos no fueron suficientes para sostener un proyecto autonómico a lo largo del tiempo. En ese sentido, afirmamos que, si bien en ciertos momentos se manifestó con claridad la transición de una condición subalterna a otra antagónica (al inicio de la organización o durante la huelga), el pasaje hacia la autonomía ha sido ambiguo. 
Aunque durante el proceso se fueron creando formas organizativas propias, estas se sostuvieron en una estructura sindical ya existente, razón por la cual el rumbo de las mismas se fue definiendo no solo en espacios asamblearios y horizontales, sino también en otras instancias que excedían a la dinámica local y que no estaban exentas de verticalismo y vicios burocráticos. A pesar de que se contara con cierta independencia para tomar decisiones en función de reivindicaciones propias, finalmente su validación y efectivización estaba sujeta a reglas y mecanismos definidos en otros niveles de la estructura organizativa. Asimismo, si en ciertos momentos las acciones traspasaron los límites institucionales adoptando una impronta movimientista, en otros casos se restringieron a los canales institucionales. Es decir, no se trató de una burocratización total ni de pura combatividad, sino de una lógica heterogénea en la que se han combinado formas diversas de consentimiento y confrontación con alcances igualmente contradictorios.

Estos elementos nos permiten identificar una situación de estancamiento (lo que definimos como estabilidad tensa) en la que se reproducen inercias que refuerzan la subalternidad y condicionan la dinámica del movimiento a lógicas externas. Ahora bien, ello no invalida que en ciertos momentos del proceso organizativo se haya logrado gestar un poder contra y un poder hacer propio. En definitiva, se puede reconocer una tendencia oscilante sin direccionalidad definida: así como la sindicalización no generó necesariamente una radicalización política, tampoco ha llevado a la apatía de los operadores telefónicos. Si bien la huelga los enfrentó a una situación límite, que fue decisiva en la orientación que tuvo dicha configuración (afirmatoria de la necesidad de autodisciplinamiento y no exposición a perder lo adquirido), también sentó un precedente de organización y lucha (la idea de un "ya basta” y "sí se puede"), que no tan fácilmente puede borrarse de la memoria afectiva. Los sentidos movilizados al calor de tal acción (creativos o no) quedan en el registro corporal como caldo de cultivo posible de ser activado en situaciones concretas. Ello confirma que la vivencia de la conflictividad, con todo su espesor, singularidad y complejidad, es fundante en la definición de una experiencia subjetiva. Como plantea Modonesi (2010), los antagonismos son el elemento dinámico que articula y da sentido a las subjetivaciones políticas: la experiencia de la lucha es sin duda alguna el factor que funda la política en un sentido amplio del término.

Finalmente, desde una lectura micropolítica, el caso descrito constata que la politización de los/as trabajadores/as ha sido un proceso contradictorio en el que se conjugaron sensibilidades, deseos y creencias que entraron en tensión entre sí y adoptaron disposiciones afectivas relativamente defensivas y reaccionarias. Desde esta perspectiva, el predominio de tales fuerzas no debería interpretarse únicamente como un resultado de la vivencia de hechos relevantes (como la huelga), sino una consecuencia de las formas en que se han entretejido los antagonismos cotidianos, dentro y fuera de los espacios de trabajo. Es decir, la desmovilización no fue una secuela de la acción descrita, sino el efecto de un conjunto de relaciones de fuerzas que en el plano micropolítico han propugnado por la conservación de las conquistas adquiridas. Ahora bien, el predominio y propagación (hasta la fecha) de tales afecciones no significa que el horizonte de las prácticas esté determinado. Las posibilidades de mutación subjetiva son múltiples y relativamente azarosas, por lo que no podemos establecer criterios a priori acerca de la direccionalidad que pudieren asumir tales configuraciones en un futuro reciente. Sin duda, sería interesante analizar en una próxima investigación el devenir de tales subjetividades teniendo en cuenta las reformas estructurales que se han implementado en el sector de telecomunicaciones en el país desde el 2013 en adelante. Esa reestructuración ha intensificado el disciplinamiento laboral en el sector, y esto podría tener impactos diversos en términos subjetivos.

\section{Agradecimientos}

Este artículo fue realizado gracias a la beca posdoctoral otorgada por el Consejo Nacional de Investigaciones Científicas y Técnicas (CONICET), Argentina. 
Anexo 1: Principales hechos del Proceso organizativo-Sindical en Tecmarketing (1997-2008).

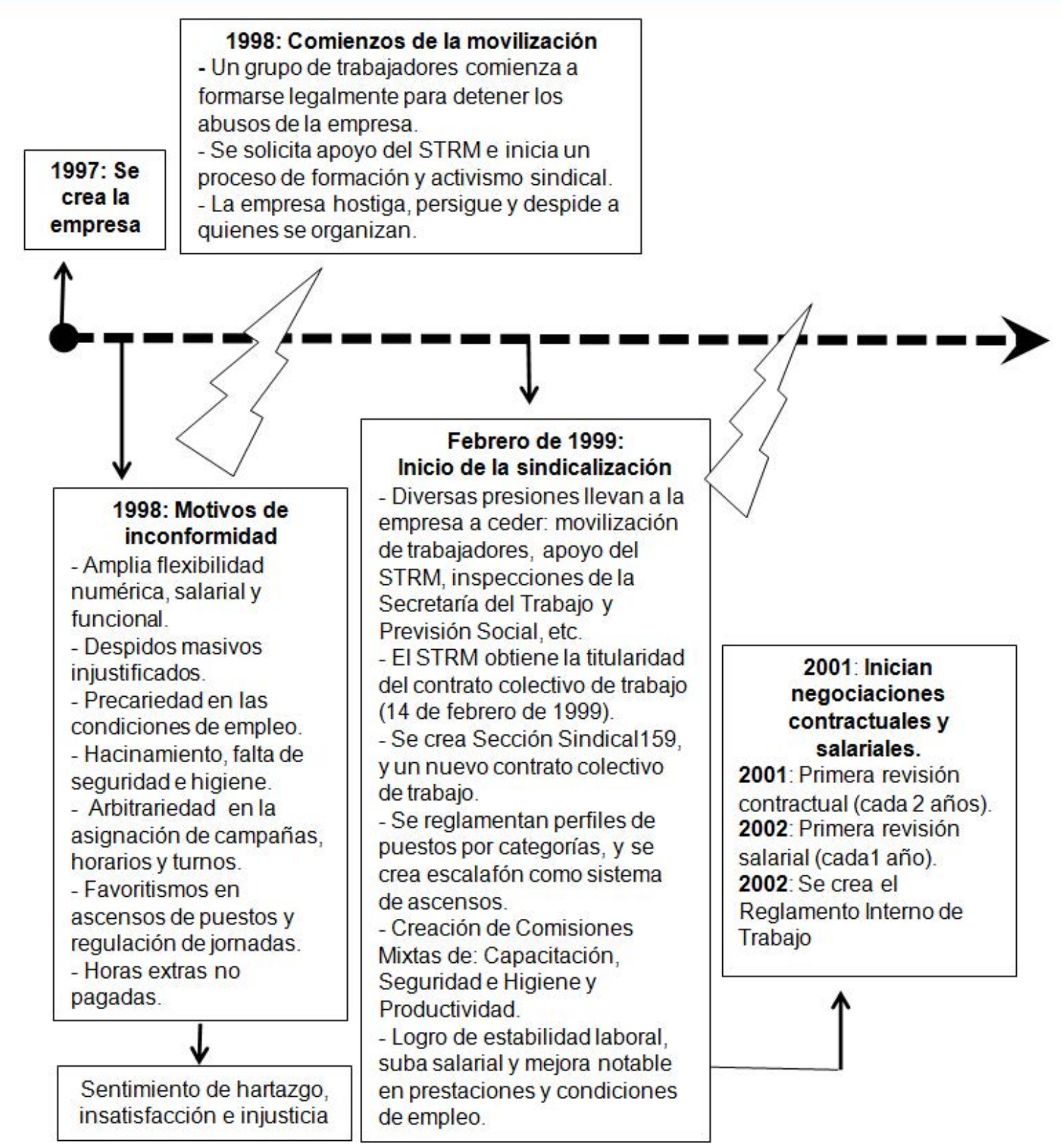

Fuente: Elaboración propia

\section{REFERENCIAS}

Bonvillani, A. (2013). Saberes apasionados. En C. Piedrahita Echandía, A. Díaz Gómez y P. Vommaro (Eds.), Acercamientos metodológicos a la subjetivación politica: debates latinoamericanos (pp. 83-100). Bogotá: Universidad Distrital Francisco José de Caldas - Consejo Latinoamericano de Ciencias Sociales.

Bourdieu, P., y Passeron, C. (2008). El ficio del sociólogo. Ciudad de México: Siglo XXI.

De la Garza, E. (2001). Subjetividad, cultura y estructura. Revista Iztapalapa, 50, 83-104. 
De la Garza, E. (2018). La metodología configuracionista para la investigación social. Ciudad de México: Universidad Autónoma Metropolitana, Gedisa.

Echeverría, B. (julio, 1996). Lo político en la política. Exposición en el Centro de Estudos Sociais de la Universidade de Coimbra, Portugal.

Lazzarato, M. (2006). Políticas del acontecimiento. Buenos Aires: Tinta Limón.

Martínez, M. C., y Cubides, J. (2012). Sujeto y política: vínculos y modos de subjetivación. Revista Colombiana de Educación, 63, 67-88.

Modonesi, M. (2010). Subalternidad, Antagonismo y Autonomía. Marxismo y subjetivación política. Buenos Aires: Prometeo, Clacso.

Modonesi, M. (2016). El principio antagonista. Marxismo y acción politica. Ciudad de México: Universidad Nacional Autónoma de México, ITACA.

Montarcé, I. (2015). Trabajo y Acción Colectiva en la maquila informacional de los Call Centers. Ciudad de México: Universidad Autónoma Metropolitana y Ediciones del Lirio.

Piedrahita Echandía, C. (2013). Reflexiones metodológicas. Acercamiento ontológico a las subjetivaciones políticas. En C. Piedrahita Echandía, A. Díaz Gómez y P. Vommaro (Eds.), Acercamientos metodológicos a la subjetivación politica: debates latinoamericanos (pp. 15-30). Bogotá: Universidad Distrital Francisco José de Caldas, Consejo Latinoamericano de Ciencias Sociales.

Piedrahita Echandía, C. (2015). Subjetivaciones politicas y pensamiento de la diferencia. Bogotá: Universidad Distrital Francisco José de Caldas, Consejo Latinoamericano de Ciencias Sociales.

Ranciére, J. (1996). El desacuerdo. Política y filosofía. Buenos Aires: Ediciones Nueva Visión.

Retamozo, M. (2006). El Movimiento de Trabajadores Desocupados en Argentina. Subjetividady acción en la disputa por el orden social (Tesis de doctorado en Investigación en Ciencias Sociales). FLACSO, Ciudad de México, México.

Retamozo, M. (2007). El método como postura. Apuntes sobre la conformación de la subjetividad epistémica y notas metodológicas sobre la construcción de un objeto de estudio. Cuaderno de Trabajo $\mathrm{N}^{\circ} 9$. Facultad de Ciencias Políticas y Sociales. Universidad Nacional Autónoma de México.

Svampa, M. (2015). Subalternidad, antagonismo y autonomía en América Latina. En M. Modonesi (Ed.), Movimientos subalternos, antagonistas y autónomos en México y en América Latina (pp.17-27). Ciudad de México: Consejo Latinoamericano de Ciencias Sociales, Universidad Nacional Autónoma de México.

Tassin, E. (2012). De la subjetivación política. Althusser / Ranciére / Foucault / Arendt / Deleuze. Revista de Estudios Sociales, 43, 36-49.

Thompson, E. P. (1989). La formación de la clase obrera en Inglaterra. Barcelona: Editorial Crítica.

Virno, P. (2003). Gramática de la multitud. Para un análisis de las formas de vida contemporáneas. Madrid: Traficantes de Sueños.

Zemelman, H. (1987). Uso crítico de la teoría. En torno a las funciones analíticas de la totalidad I. Ciudad de México: El Colegio de México.

Zemelman, H. (2012). Subjetividad y realidad social. En C. Piedrahita Echandía, A. Díaz Gómez y P. Vommaro (Eds.), Subjetividades políticas: desafios y debates latinoamericanos (pp. 235-246). Bogotá: Universidad Distrital Francisco José de Caldas, Consejo Latinoamericano de Ciencias Sociales. 